\title{
FREQUENCY OF CELIAC DISEASE; PATIENTS PRESENTING WITH IRON DEFICIENCY ANEMIA AT TERTIARY CARE HOSPITAL
}

1. Assistant Professor Department of Medicine Peoples University of Medical \& Health

Sciences for Women

Nawabshah, Sindh, Pakistan

2. FCPS (Medicine), (MSc GASRTO)

Consultant Gastroenterologist Asian Institute of Medical Sciences (AIMS)

Hyderabad, Sindh, Pakistan

3. Post-graduate Student Department of Medicine Peoples University of Medical \& Health

Sciences for Women

Nawabshah, Sindh, Pakistan

Correspondence Address:

Dr. Abdul Aziz Sahto

FCPS (Medicine), (MSc GASRTO)

Consultant Gastroenterologist

Asian Institute of Medical Sciences (AIMS)

Hyderabad, Sindh, Pakistan

draasahito1111@gmail.com

Article received on:

28/03/2016

Accepted for publication:

20/05/2016

Received after proof reading: 04/07/2016

\section{Dr. Amir Shahzad1, Dr. Abdul Aziz Sahto², Dr. Samina ${ }^{3}$}

ABSTRACT... Objectives: The aim behind this study was to determine the frequency of Celiac disease in patients presenting with Iron deficiency anemia at tertiary care hospital. Study Design: Descriptive cross sectional hospital based study. Setting: Non-probability consecutive sampling technique in a department of medicine at Medical Unit II, People's Medical University, Shaheed Benazeerabad. Period: Six months from $26^{\text {th }}$ October 2014 to $25^{\text {th }}$ April 2015. Patients and Methods: A standard sample bottle was used to collect the blood sample from the peripheral vein followed by testing for Anti-tissue transglutaminase antibodies (tTG) and anti-endomysial antibodies (EMA). On these patients upper GI endoscopy for jejunal biopsy was done by an expert having an experience of $>5$ years in relevant field. Data regarding Hemoglobin, anti tTG antibodies, anti Endomysial antibodies and diagnosis of celiac disease (outcome variable) were collected. Data were entered and analyzed by using Statistical Package for the Social Sciences version 20.0. Results: Out of total 77 patients, the mean age and SD of age and hemoglobin levels were $37.65 \pm 11.26$ years and $8.81 \pm 1.23 \mathrm{~g} / \mathrm{dl}$, respectively. Celiac disease (CD) Positive finding was observed in $27.27 \%$ cases by anti-tTG antibodies and in $16.88 \%$ cases by anti-endomysial antibodies. Prevalenc Frequency of celiac disease in patients presenting with iron deficiency anemia was observed in Around 12.99\% (10/77) of the cases who had underlying iron deficiency anemia were observed to have concomitant. Conclusion: There is a high prevalence of Celiac disease in patients presenting with Iron deficiency anemia. Early deduction and prompt treatment should be necessary for this disease. Screening of celiac disease by anti-tissue transglutaminase antibody should be done as a routine investigation in patient with iron-deficiency anemia.

Key words: $\quad$ Celiac disease, Iron deficiency anemia, Anti-tissue transglutaminase, antiendomysial antibodies

Article Citation: Shahzad A, Sahto AA, Samina. Frequency of celiac disease; patients presenting with iron deficiency anemia at tertiary care hospital. Professional Med J 2016;23(7):812-816. DOI: 10.17957/TPMJ/16.3375

\section{INTRODUCTION}

Celiac disease (celiac sprue or gluten sensitive enteropathy; CD) is an immunologically mediated inflammatory disorder of the small bowel occurring in genetically susceptible individuals and resulting from intolerance to wheat gluten and similar proteins found in rye and barley. ${ }^{1}$

The clinical presentation of CD is highly variable. It depends on the severity and extent of small intestine involvement. Patients may have florid malabsorption; or may develop non-specific symptoms such as tiredness, weight loss, folate deficiency or iron deficiency anemia. ${ }^{2-4}$

Iron deficiency anemia (IDA) is a characteristic complication of $\mathrm{CD}$ especially pertaining to the developing countries where $C D$ is on rise while iron deficiency is also very common. In CD due to destruction of proximal small intestine mucosal surface, the absorption of iron is deficient. More recently it was found that out of all IDA patients, $15 \%$ were positive for celiac disease in a study. ${ }^{5-7}$

Iron deficiency anemia is quite common in our country but most of times it goes undiagnosed and therefore not properly treated. This increases the morbidity on the one hand and financial burden on the other. Much proportion this extra burden can be contributed to celiac disease. Upon through literature no sufficient data was found at local level which could estimate the 
burden of CD in patients who are diagnosed with IDA. This provides a strong rationale to this study. If the results of this study show that the magnitude of burden of celiac disease in patients of IDA is frequent then the screening of all IDA patients will be recommended in our set up.

\section{PATIENTS AND METHODS}

This is a descriptive cross sectional hospital based study carried out through a non-probability consecutive sampling technique in the department of Medicine at Medical Unit II, People's Medical University, Shaheed Benazeerabad between the periods of six months from $26^{\text {th }}$ October 2014 to $25^{\text {th }}$ April 2015.

We have evaluated a total of 77 patients of iron deficiency anemia having age between 18 to 60 years of either gender after taking their informed consent. Those patients who had a history of gastric/intestinal surgery, taking iron supplements, women with irregular menstrual disorders like hypermenorrhagia, i.e. menstrual cycle $>7$ days, history of bleeding per rectum, hematemesis, melena, hematuria, hematological malignancy (leukemia, lymphoma or bleeding disorders like Hemophilia), chronic liver infections/disease (HBV, HCV, Cirrhosis), and other chronic diseases like; Renal failure and heart failure were excluded from the study.

Study was started after approval from the Ethical committee of the hospital. Patients presenting to OPD of medical unit-II, People's University of Medical and Health Sciences, Shaheed Benazeerabad, who fulfilled the selection criteria was asked to participate in the study after explaining the objectives of the study. Those who provide consent were included in the study. Predesigned proforma was used to collect the data. The data was collected on demographic variables like name, age, gender, residence.

Complete history and thorough physical examination including the GIT \& oral cavity was done. A standard sample bottle was used to collect the blood sample from the peripheral vein followed by testing for Anti-tissue transglutaminase antibodies (tTG) and anti-endomysial antibodies (EMA). On these patients upper Gl endoscopy for jejunal biopsy was done by an expert having an experience of $>5$ years in relevant field. Data regarding Hemoglobin, anti tTG antibodies, anti Endomysial antibodies, and diagnosis of celiac disease (outcome variable) were collected.

\section{DATA ANALYSIS}

SPSS version 20.0 was used to analyze the data. Continuous variables like age and hemoglobin levels were analyzed as mean ( \pm SD). Frequency \& percentages were expressed for categorical variables like gender, residence, Anti tTG antibodies, Anti Endomysial antibodies \& diagnosis of celiac disease (outcome variable). The study participants were enrolled through strictly following the selection criteria to control the confounding factors.

To evaluate the effect modification of frequency of celiac disease (outcome variable), age of patient, gender \& hemoglobin levels were stratified followed by application of Chi-square test with $P$ value $<0.05$ as significant.

\section{RESULTS}

A total of 77 patients with diagnosed cases of Iron deficiency anemia since greater than three month period were included in this study. Most of the patients were below 30 years and 31 to 40 years of age as presented in figure-1. The mean age of the patients was $37.65 \pm 11.26$ years and mean hemoglobin level was $8.81 \pm 1.23 \mathrm{~g} / \mathrm{dl}$ as shown in table-l. Out of 77 cases, 44 (57.14\%) were male and 33 (42.86\%) were female as shown in table-I. Celiac disease (CD) Positive finding was observed in $27.27 \%$ cases by anti tTG antibodies (figure-2) and in $16.88 \%$ cases by anti endomysial antibodies as presented in figure-3.

Frequency of celiac disease in patients presenting with iron deficiency anemia was observed in $12.99 \%(10 / 77)$ cases (figure 4). Rate of CD was also not significant between different HB level and gender as presented in table-II. 


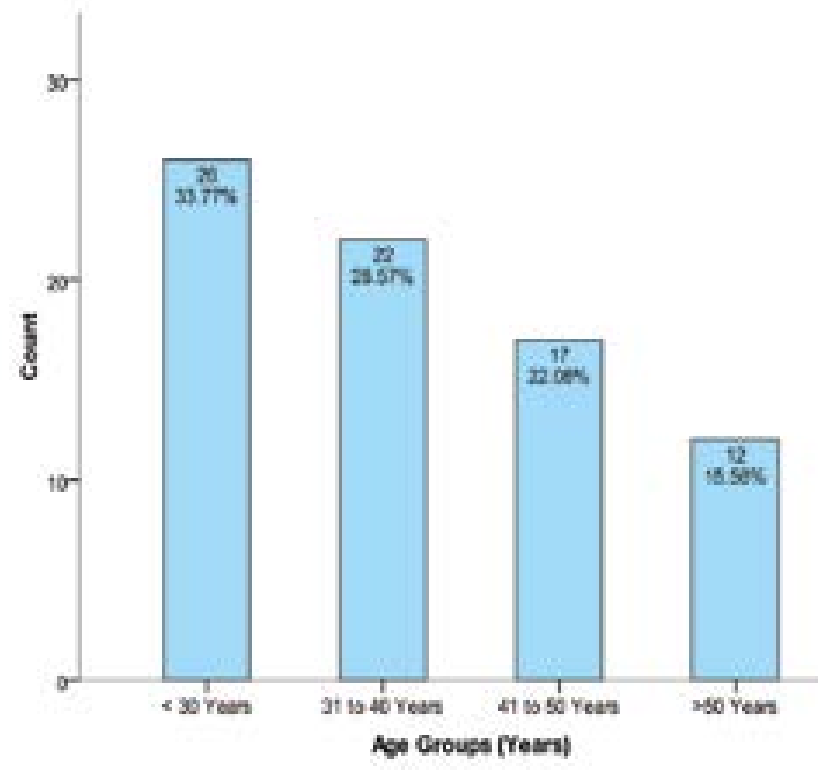

Figure-1. Different age groups of study subjects:

\begin{tabular}{|l|c|c|}
\hline \multicolumn{1}{|c|}{ Statistics } & Age (Year) & HB (gm/dl) \\
\hline Mean & 37.65 & 8.81 \\
\hline Median & 36 & 9 \\
\hline Standard Deviation & 11.26 & 1.23 \\
\hline Minimum & 18 & 7 \\
\hline Maximum & 60 & 12 \\
\hline Gender & Number & Percentage \\
\hline Male & 44 & 57.14 \\
\hline Female & 33 & 42.86 \\
\hline
\end{tabular}

Table-I. Baseline characteristics of study subjects:

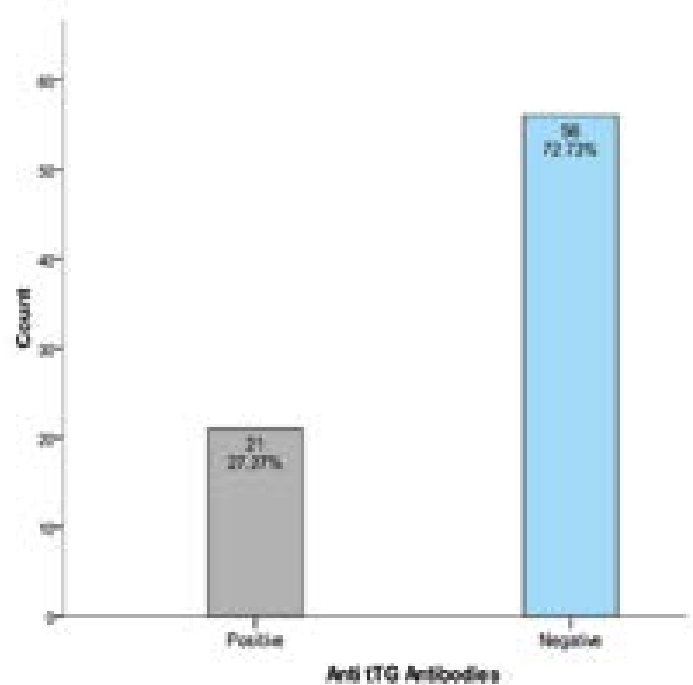

Figure-2. Frequency of Anti-TTG antibodies $(n=77)$

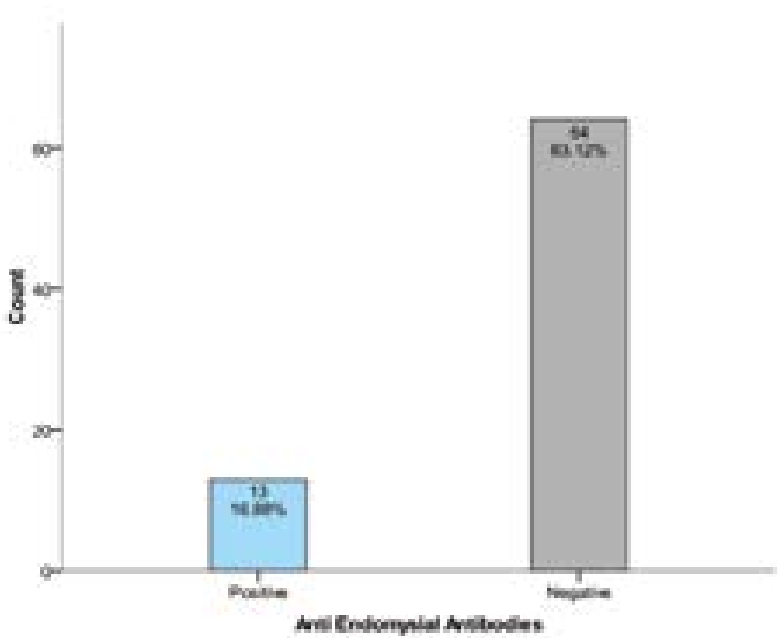

Figure-3. Frequency of positive Anti-Endomysial Antibodies $(n=77)$

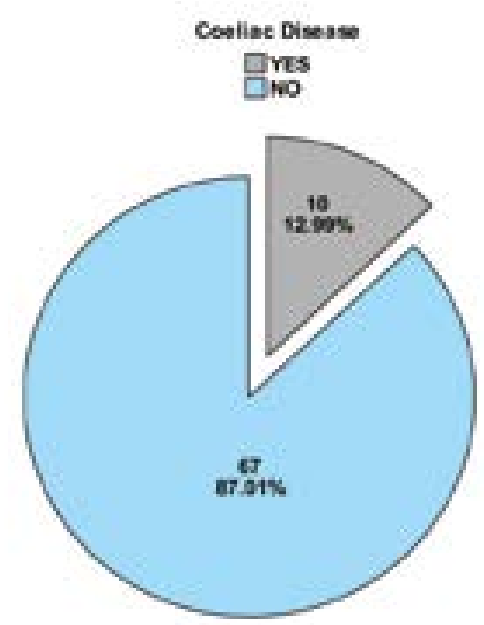

Figure-4. Frequency of celiac disease in patients presenting with iron deficiency anemia $(n=77)$

\begin{tabular}{|c|c|c|c|}
\hline HB & \multicolumn{2}{|c|}{ Celiac Disease } \\
\hline & $\begin{array}{c}\text { Yes } \\
n=10\end{array}$ & $\begin{array}{c}\text { No } \\
n=67\end{array}$ & Total \\
\hline$\leq 9$ & $8(13.6 \%)$ & $51(86.4 \%)$ & 59 \\
\hline $10-12$ & $2(11.1 \%)$ & $16(88.9 \%)$ & 18 \\
\hline Table-II. Frequency of celiac disease in patients \\
presenting with iron deficiency anemia with respect to \\
HB \\
\hline \multicolumn{3}{|c|}{ Chi-Square=0.073; $p=0.787$} \\
\hline
\end{tabular}

\section{DISCUSSION}

In celiac disease there will be intolerance to dietary gluten, which is a major storage form of a protein especially found in wheat. ${ }^{8,9}$ In United 
States estimated scientific data suggest that $\sim 1 \%$ of the general population has celiac disease..$^{9,10}$

In this study the mean age of the patients was $37.65 \pm 11.26$ years and mean hemoglobin level was $8.81 \pm 1.23 \mathrm{~g} / \mathrm{dl}$. It was also observed in Zamani et al $^{17}$ study mean age was $37.6 \pm 19.8$ years. In Harper et al $^{11}$ study mean age was 46.5 \pm 16.2 years.

Studies that have been conducted previously have shown the burden iron deficiency anemia those who had celiac disease as 12 and 69 in Pakistan. ${ }^{12,13}$ Various rates of prevalence of CD in IDA patients have been reported among different studies.

In present study frequency of celiac disease in patients presenting with iron deficiency anemia was observed in $12.99 \%$ (10/77) cases. More recently it was found that out of all IDA patients, $15 \%$ were positive for celiac disease in a study by Zamani $\mathrm{F}$, et $\mathrm{al}^{14}$ It was significantly proved when the mean hemoglobin levels of $14 \%$ of these patients increased from $9.9 \pm 1.6$ to $12.8 \pm 1.0 \mathrm{~g} /$ $\mathrm{dl}$ (within 6 months; $\mathrm{P}<0.01$ ) when they were only kept on gluten free diet (No iron supplementation given).

In this study rate of CD was also not significant between different HB level and gender. Our study findings are consistent with the study conducted previously that which concluded that more females are affected than males in celiac disease due to underlying malabsorption. ${ }^{15}$

\section{CONCLUSION}

There is a high prevalence of Celiac disease in patients presenting with Iron deficiency anemia. Early deduction and prompt treatment should be necessary for this disease. Screening of celiac disease by anti-tissue transglutaminase antibody is supposed to be done as a baseline investigation in patient with iron-deficiency anemia.

\section{Copyright@ 20 May, 2016.}

\section{REFERENCES}

1. Sanchez-Vargas LA, Thomas-Dupont P, Torres-Aguilera M, Azamar-Jacome AA, Ramirez-Ceervanes KL, Aedo-
Garces MR, et al. Prevalence of celiac disease and related antibodies in patients diagnosed with irritable bowel syndrome according to the Rome III criteria. A case-control study. Neurogastroenterol Motil 2016 Feb 23.

2. Rodriguez AJ, Hernandez MA, Lucendo AJ, Casellas F, Solano Ruiz MC, Siles GJ. Health-related quality of life and determinant factors in celiac disease. A population-based analysis of adult patients in Spain. Rev Esp Enferm Dig 2016 Feb 22;108.

3. Singh I, Agnihotri A, Sharma A, Verma AK, Das P, Thakur $B$, et al. Patients with celiac disease may have normal weight or may even be overweight. Indian $\mathrm{J}$ Gastroenterol 2016 Feb 18.

4. Fueyo DR, Gascon SS, Asensio MA, Sanchez Calavera MA, Magallon BR. Transcultural adaptation and validation of the Celiac Dietary Adherence Test. A simple questionnaire to measure adherence to a gluten-free diet. Rev Esp Enferm Dig 2016 Mar;108(3):138-44.

5. Baghbanian M, Farahat A, Vahedian HA, Sheyda E, Zare-Khormizi Mr. The prevalence of celiac disease in patients with iron-deficiency anemia in center and south area of iran. Arq Gastroenterol 2015 Dec;52(4):278-82.

6. Sanseviero MT, Mazza GA, Pullano MN, Oliveiro AC, Altomare $F$, Pedrelli $L$, et al. Iron deficiency anemia in newly diagnosed celiac disease in children. Minerva Pediatr 2016 Feb;68(1):1-4.

7. Subramaniam G, Girish M. Iron deficiency anemia in children. Indian J Pediatr 2015 Jun;82(6):558-64.

8. Green PH, Jabri B. Coeliac disease. Lancet 2003 Aug 2;362(9381):383-91.

9. Fasano A, Berti I, Gerarduzzi T, Not T, Colletti RB, Drago $S$, et al. Prevalence of celiac disease in atrisk and not-at-risk groups in the United States: a large multicenter study. Arch Intern Med 2003 Feb 10;163(3):286-92.

10. West J, Logan RF, Hill PG, Lloyd A, Lewis S, Hubbard R, et al. Seroprevalence, correlates, and characteristics of undetected coeliac disease in England. Gut 2003 Jul;52(7):960-5.

11. Harper JW, Holleran SF, Ramakrishnan R, Bhagat G, Green $\mathrm{PH}$. Anemia in celiac disease is multifactorial in etiology. Am J Hematol 2007 Nov;82(11):996-1000.

12. Ciacci C, Cirillo M, Sollazzo R, Savino G, Sabbatini F, Mazzacca G. Gender and clinical presentation in adult celiac disease. Scand J Gastroenterol 1995 
Nov;30(11):1077-81.

13. Bottaro G, Cataldo F, Rotolo N, Spina M, Corazza GR. The clinical pattern of subclinical/silent celiac disease: an analysis on 1026 consecutive cases. Am J Gastroenterol 1999 Mar;94(3):691-6.

14. Zamani F, Mohamadnejad M, Shakeri R, Amiri A, Najafi $S$, Alimohamadi SM, et al. Gluten sensitive enteropathy in patients with iron deficiency anemia of unknown origin. World J Gastroenterol 2008 Dec 28;14(48):73815.

15. Bai D, Brar P, Holleran S, Ramakrishnan R, Green PH. Effect of gender on the manifestations of celiac disease: evidence for greater malabsorption in men. Scand J Gastroenterol 2005 Feb;40(2):183-7.

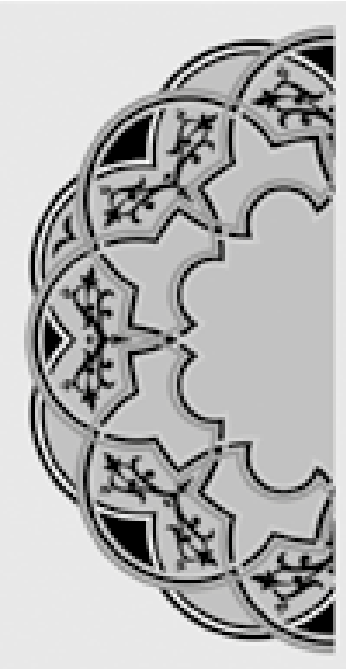

\title{
"Be a good person but don't
} waste time to prove it."

\author{
Robert F. Kennedy
}

\section{AUTHORSHIP AND CONTRIBUTION DECLARATION}

\begin{tabular}{|c|l|l|l|}
\hline Sr. \# & \multicolumn{1}{|c|}{ Author-s Full Name } & \multicolumn{1}{|c|}{ Contribution to the paper } & Author=s Signature \\
\hline 1 & Dr. Amir Shahzad & $\begin{array}{l}\text { All authors have } \\
\text { contributed equally }\end{array}$ \\
\hline 2 & Dr. Abdul Aziz Sahto & \\
\hline 3 & Dr. Samina & \\
\hline
\end{tabular}

